\title{
The Cost Effectiveness of Biologic Therapy for the Treatment of Chronic Plaque Psoriasis in Real Practice Settings in Italy
}

\author{
Federico Spandonaro $\cdot$ Fabio Ayala $\cdot$ Enzo Berardesca $\cdot$ Sergio Chimenti $\cdot$ \\ Giampiero Girolomoni - Patrizia Martini - Andrea Peserico - Barbara Polistena • \\ Antonio Puglisi Guerra • Gino Antonio Vena · Gianfranco Altomare • \\ Piergiacomo Calzavara Pinton
}

Published online: 25 February 2014

(C) The Author(s) 2014. This article is published with open access at Springerlink.com

\begin{abstract}
Background and Objectives Biologic therapies are considered to be cost effective by leading Health Technology Assessment (HTA) agencies and, therefore, eligible for reimbursement by public health services. However, biologic therapies entail sizable incremental costs and, besides, have a considerable financial impact that in Italy amounts to $13.7 \%$ of the national health service's pharmaceutical expenditure. In the reimbursability decision process, an important role is played by both the drug efficacy data observed in pre-licensing RCTs and the economic modelling assumptions, as they give evidence on cost effectiveness. The administration of therapies in real practice settings is likely to produce a significant deviation from the results predicted by the models, theoretically outweighing
\end{abstract}

\footnotetext{
F. Spandonaro $(\bowtie) \cdot$ B. Polistena

University of Rome Tor Vergata, Via Columbia 2, 00133 Rome, Italy

e-mail: federico.spandonaro@uniroma2.it

F. Ayala

Department of Dermatology, University of Naples Federico II,

Naples, Italy

E. Berardesca

San Gallicano Dermatological Institute, Rome, Italy

S. Chimenti

Department of Dermatology, University of Rome "Tor

Vergata", Rome, Italy

G. Girolomoni

Department of Medicine, Section of Dermatology and

Venereology, University of Verona, Verona, Italy

P. Martini

Unit of Dermatology, Lucca Hospital, Lucca, Italy
}

the assumption on which the decision process is founded. This is a matter of concern for public health services and, consequently, an interesting topic to investigate.

Methods To overcome the lack of knowledge concerning the actual cost effectiveness of biologic therapies for the treatment of plaque psoriasis in the clinical practice setting in Italy, an observational study was conducted in 12 specialist centres on patients switching to biologic therapy within a 6-month enrolment window.

Results The study confirms in clinical practice the efficacy of the switch to biologic therapies, analysed using a number of clinical [Psoriasis Area and Severity Index (PASI), pain visual analogue scale (VAS) and itching VAS] and quality-of-life parameters. A general healthrelated quality of life (HR-QOL) improvement, with a 0.23
A. Peserico

Unit of Dermatology, Department of Medicine, University of Padua, Padua, Italy

A. Puglisi Guerra

Department of Dermatology, Messina Hospital, Messina, Italy

G. A. Vena

Dermatology and Venereology Private Practice, Bari, Italy

G. A. Vena

Dermatology and Venereology Private Practice, Barletta, Italy

G. Altomare

Department of Dermatology, IRCCS Galeazzi Orthopedic Institute, Milan, Italy

P. Calzavara Pinton

Department of Dermatology, Spedali Civili, Brescia, Italy 
quality-adjusted life-year (QALY) mean gain per patient, has been reported in the 6-month observation period. The direct medical costs to treat plaque psoriasis with biologic therapies amount to $€ 15,073.7$ per year (prior to their enrolment, the same patients cost $€ 2,166.2$ on an annual basis). After the switch to biologic agents, the cost per QALY during the first year of treatment amounts to $€ 28,656.3$.

Conclusion At least in the short-term, the clinical practice of the specialised Italian centres taking part in the study confirms that switching patients to a biologic drug produces an incremental cost-effectiveness ratio comparable with the values predicted by the HTA bodies.

\section{Introduction}

Psoriasis is one of the most common forms of chronic dermatitis, affecting $2-3 \%$ of the population $[1,2]$. It is a chronic, non-infectious inflammatory skin disease, with a relapsing-remitting course, meaning that psoriatic patients are never 'cured', rather they experience periods in which the effects of the illness are less obvious, alternating with periods in which they experience a flare-up [3]. The aetiology of psoriasis is still unclear and the data available at the current time suggest a multifactorial origin. Psoriasis is common amongst young individuals and is associated with a higher risk of cardiovascular events [4] and depressive symptoms [5].

The most common form of the condition is psoriasis vulgaris or plaque psoriasis, which accounts for $80 \%$ of all cases [6]. In general, psoriasis is usually classified as mild, moderate or severe, depending on the surface area affected, redness, and the thickness and desquamation of the plaques. A number of instruments have been devised to define the severity of the disease and compare scores over time for the same patient and between patients [7].

Patients with forms of psoriasis refractory to topical treatments and with extensive lesions are usually switched to systemic oral or intravenous medications and UV light treatment. The systemic treatments used are immunomodulators cyclosporin (ciclosporine) and methotrexate, and the retinoid acitretin. Although administration is most commonly oral, these treatments must be administered under medical supervision and require regular monitoring to exclude the presence of infections. Patients with an inadequate response to systemic therapy or those presenting with contraindications to or who are intolerant to this kind of treatment are treated with biologic therapies. Biologic medications interfere in a selective way on various levels and with different actions on the pathological immunological processes that trigger and sustain psoriasis [8].
Given the high prevalence of psoriasis in the general population, its management in terms of medical and social costs is also of significant importance to society in general.

A comparative study conducted in 2004 [9] analysing the treatment of severe psoriasis (approximately 27-30\% of psoriasis patients) in seven European countries (France, Germany, Holland, Spain, Sweden, England and Italy), showed a large variability, with a mean annual cost per patient that ranged from $€ 2,981$ in France to $€ 6,595$ in Sweden, with a value of $€ 3,712$ in Italy. These figures underestimate the actual costs, as the study did not consider the costs sustained directly by patients, the costs of patients for whom psoriasis was a secondary diagnosis or the costs of treatment of any side effects of therapy. The cost-ofillness study conducted by Colombo et al. [10] estimated that moderate and severe psoriasis costs the Italian national health service (NHS) €2,403 million per year, equivalent to $1.8 \%$ of total spending on health in 2007 , and also confirmed that these costs were primarily for hospitalisation, followed by laboratory tests and systemic medication for a mean annual total of $€ 8,372$ per patient, of which $68 \%$ $(€ 5,690)$ were direct costs. In this analysis no patient was treated with biologic drugs.

CESAV (Centro di Economia Sanitaria A. e A. Valenti) [11], which assumed psoriasis has a prevalence of $3 \%$ in the Italian population between 20 and 80 years of age, estimated the annual direct costs incurred by the Italian health service in 2008 for each patient with moderate or severe psoriasis to be $€ 4,565.5$ (of which $94.6 \%$ was for drugs and 3.8 and $1.6 \%$ was for outpatient clinical and hospital care, respectively). Consequently, the total cost of plaque psoriasis borne by the Italian health service, for moderate and severe patients only, would be $€ 680$ million.

The two studies show significant differences, both in the prevalence of moderate and severe psoriasis, and in costs for patients.

Biologic therapies are very expensive and, nowadays, their financial impact is relevant: in the Italian NHS biologic drugs amount to $€ 30.1$ per capita $(13.7 \%$ of the Italian NHS pharmaceutical expenditure). In particular, agents considered in this study represent $28.9 \%$ of the expenditure for biologic drugs.

Despite the increasing costs implied, biologic drugs are reimbursed by most public health services, following evidence on their cost effectiveness as assessed by leading Health Technology Assessment (HTA) agencies.

In the decision process, efficacy data of drugs observed in pre-licensing randomised controlled trials (RCTs) and subsequent economic modelling play an important role. On the other side, possible deviations from model-predicted results, due to administration of therapies in a real population and in real practice settings, is an interesting topic and a potential matter of concern for public health services. 
The aim of this study is to investigate the cost effectiveness of biologic therapy for the treatment of chronic plaque psoriasis in real practice settings for a caseload of Italian specialised centres.

The novel aspect of the study lies in the lack of studies considering the cost effectiveness of biologic therapy in clinical practice settings, as well as the shortage of information on the benefits of these agents in terms of quality of life in the Italian population.

\section{Methods}

\subsection{Study Design}

A prospective observational study was conducted to evaluate the direct medical costs and health-related quality of life (HR-QOL) of patients with chronic plaque psoriasis switching to treatment with biologics, with the aim of providing some economic insight, from the Italian NHS perspective, using a cost-utility approach.

The study enrolled all patients switching de novo to biologic therapy between 11 May and 31 December 2009 and all those who, during the same period, reverted to biologic treatment after at least 1 year's suspension. Eligibility to switch and the treatment administered was up to the physician's discretion. Enrolled patients were observed for 6 months.

The analysis was conducted in 12 specialised centres, members of the Psocare ${ }^{1}$ network, located in different parts of Italy.

The significance of the differences in the mean values between the pre-enrolment and follow-up periods was assessed using the paired samples $t$-test, whereas the significance of the difference in mean values between the subgroups of patients taking the various biologics was evaluated using the one-sample $t$-test. More specifically, normality was analysed using the Kolmogorov-Smirnov test and the homogeneity of variance using Levene's test. When normality was refuted, non-parametric one-sample tests were performed.

\footnotetext{
1 The Psocare project was launched as part of a programme promoted by the Italian Agency of Drugs (AIFA) and organised in association with dermatology societies and patient associations, under the technical coordination of the GISED (Gruppo Italiano Studi Epidemiologici in Dermatologia) research centre. Psocare was based on the philosophy that the psoriasis treatment strategies devised thus far have resulted in the consolidation of habits or behaviour amongst doctors rather than in clear outcomes in terms of efficacy. The aim of the project was therefore to evaluate the long-term efficacy and safety of the treatments available. The approach used is based on comparisons between different care strategies, with a view to obtaining a realistic estimate of their benefits and risks. The information collected in the Psocare project is therefore of great value when evaluating the outcomes of the treatments provided to psoriatic patients.
}

\subsection{Data Collection}

\subsubsection{Demographics and Clinical Characteristics at Enrolment}

Upon enrolment in the study, and before switching to biologic therapy, questionnaires were administered using the Computer-Assisted Personal Interviewing (CAPI) method to evaluate patients' HR-QOL and clinical conditions, including both subjective patient assessments and objective physician-assessed measures. Those completed by patients included general details and socioeconomic data, as well pain and itching visual analogue scales (VAS) and information on drugs used. Those completed by doctors involved the main elements of clinical evaluation [Psoriasis Area and Severity Index (PASI)].

At the end of the 6-month follow-up period, patients were asked to repeat the HR-QOL and clinical status questionnaires and information was collected about any treatment combinations and the reasons for withdrawal, where applicable; the objective severity of the condition was re-evaluated using the PASI score, and the pain and itching VAS scores were used to acquire a subjective evaluation.

\subsubsection{Quality of Life and Cost Data}

Direct medical costs included all costs used in connection with psoriasis: hospitalisation, day hospital and/or outpatient services, specialist appointments, laboratory tests, diagnostic procedures, phototherapy and drugs.

For the 6-month follow-up period, the actual costs of psoriasis treatment after switching to biologic therapy were collected prospectively, while utilisation of healthcare resources per patient in the 6 months $^{2}$ prior to the start of biologic therapy were calculated retrospectively. All costs were quantified in terms of burden on the Italian health service and were calculated using the applicable Italian health service list of charges.

HR-QOL was elicited using the European Quality of Life Questionnaire [12] at baseline (at the time of switch from systemic to biologic therapies) and quality-adjusted life-years (QALYs) were calculated after 6 months.

\subsubsection{Cost Analysis}

A cost-utility approach was used by comparing [using the incremental cost-effectiveness ratio (ICER)] the change in

\footnotetext{
2 To avoid statistical bias due to patients' lack of memory regarding minute resource utilisation, data on laboratory services and visits were collected, asking for consumption in the previous 3 months, then assuming constant treatment.
} 
HR-QOL attributed to treatment (expressing the benefits in terms of QALYs) with the increase in costs. The ICER was also calculated with alternative measurements of effectiveness obtained using the PASI and pain and itching VAS scores. The costs refer to year 2009.

\section{Results}

\subsection{Baseline Data}

A total of 185 patients were enrolled, with a minimum of seven and a maximum of 43 patients enrolled per centre. However, the analysis was performed on 178 patients as one centre withdrew before the end of the project. All patients completed the follow-up period.

Patients were between 18 and 79 years of age, with a median age of 49.5 years [mean 47.7 years $\left.\left(\sigma^{2}=192.6\right)\right]$. The median age at diagnosis was 28.0 years [mean 30.6 years; range $1-70$ years $\left.\left(\sigma^{2}=211.7\right)\right]$. Although the literature suggests that prevalence is similar for both sexes [13], in this study males were more prevalent, accounting for $64.6 \%$ of the total cohort (Table 1).

At enrolment, i.e. the switch to treatment with a biologic agent, $59.6 \%$ of patients were prescribed etanercept, $32.0 \%$ adalimumab and $8.4 \%$ received infliximab. ${ }^{3}$

\subsection{Efficacy Data}

Between the start of treatment with a biologic and the end of the follow-up period, all subjective and objective measurements of clinical status improved. Patients' mean PASI scores dropped significantly from 21.6 to $9.0(p=0.000)$. More specifically, during the 6-month observation period, the number of patients with a PASI score $<10$ rose by $155.8 \%$, those with a PASI between 10 and 20 by $13.0 \%$, and patients with a PASI of between 20 and 30 and $>30$ dropped by $76.1 \%$ and $86.0 \%$, respectively.

There was also a significant drop in the mean pain VAS score, which fell from 28.5 to $8.8(p=0.000)$. During the observation period, the proportion of patients with a pain VAS score $<24$ rose by $50.0 \%$, those with a score of 25-49 dropped by $47.1 \%$, those with a score of 50-74 dropped by $72.4 \%$ and those with a score of $75-100$ dropped by $82.1 \%$.

As regards the itching VAS, once again there was a significant reduction in the average score, which dropped from 31.7 to $7.7(p=0.000)$. During the observation

\footnotetext{
${ }^{3}$ Efalizumab, which was considered an alternative at the time the research protocol was devised, was not prescribed to any patient due to publication of a pharmacovigilance order by AIFA before enrolment started.
}

Table 1 Characteristics of the enrolled cohort

\begin{tabular}{ll}
\hline Variable & Value \\
\hline$N$ & 178 \\
Mean age, years (range) & $47.7(18-79)$ \\
Mean age at diagnosis, years & 30.6 \\
Males, \% & 64.6 \\
\hline
\end{tabular}

period, patients with a pain VAS score $<24$ rose by $94.0 \%$, those with a score of $25-49$ dropped by $86.0 \%$, those with a score of 50-74 dropped by $80.6 \%$ and those with a score of 75-100 dropped by $75.0 \%$.

\subsubsection{Differences Among the Biologics Used}

We noted that significant improvements in efficacy were observed for all three agents; however, differences between agents were not statistically significant. Patients who were prescribed etanercept at enrolment had a higher mean PASI than those prescribed adalimumab and infliximab (23.6, 18.0 and 21.0, respectively). During the 6-month observation period, there was a benefit in terms of a reduction in PASI of 14.4 for etanercept, 9.8 for adalimumab and 10.8 for infliximab (Fig. 1). Similarly for the pain VAS, the greatest benefit was observed for patients taking etanercept (from 31.5 to 7.7), followed by adalimumab (from 24.2 to 9.7 ) and infliximab (from 25.5 to 13.5) (Fig. 2).

For adalimumab and etanercept (the number of patients enrolled who received infliximab was lower) there was also a significant reduction in the itching VAS score, where once again the greatest benefit was observed for patients taking etanercept (from 34.0 to 7.2), followed by adalimumab (from 27.1 to 8.3 ) and infliximab (from 32.9 to 8.7) (Fig. 3).

In Figs. 1, 2 and 3, each box shows the maximum value, upper quartile, mean (red diamonds), lower quartile and minimum value, and eventual outliers.

\subsection{Quality-of-Life Data}

During the 6-month observation period there was a general improvement in HR-QOL, with a mean gain of 0.23 QALY per patient $(p=0.000)$. The number of patients with an HR-QOL $<0.25$ dropped by $76.3 \%$, those with an HRQOL of $0.25-0.50$ by $50.0 \%$ and those with an HR-QOL of $0.50-0.75$ by $44.9 \%$, with a consequential $125.9 \%$ increase in those with an HR-QOL of 0.75 .

For all three agents, the improvement in the quality of life measured using the EQ-5D questionnaire was statistically significant, with non-statistically significant differences between them; the greatest benefit was observed for 


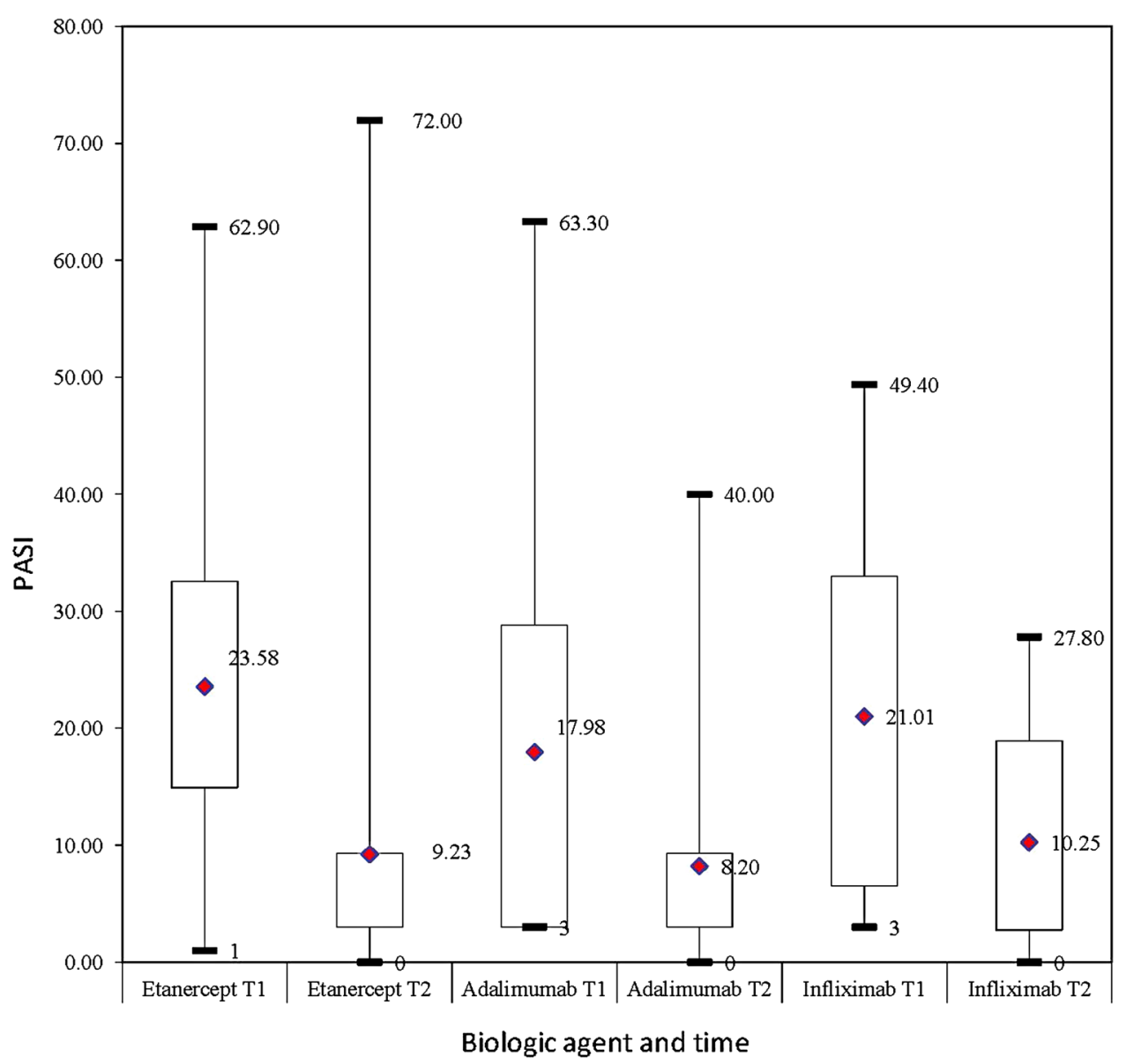

Fig. 1 Psoriasis Area and Severity Index (PASI) level

patients on etanercept ( 0.23 QALYs) versus 0.21 for adalimumab and infliximab (Tables 2 and 3).

\subsection{Cost Analysis}

Costs recorded for the 6-month period were annualised to permit easier comparison with other studies; we have assumed cost constancy over time, except in one case for drugs costs, because it seems appropriate to consider the intermittent administration of etanercept as provided in the technical file. In other words, for etanercept, which was the only drug approved in Italy for intermittent treatment [14], it was assumed that patients took $50 \mathrm{mg}$ twice a week for 12 weeks, then $50 \mathrm{mg}$ once a week for a further 12 weeks, before interrupting treatment for at least 3 months, the mean time for any recurrence. It should be noted that it was not possible to confirm this behaviour in clinical practice, due to the insufficient duration of the follow-up period. The assumption would appear to be fairly conservative, as it assumes that all patients continue with the treatment, whereas only $14 \%$ of patients [15] experience a recurrence.

Before enrolment, the mean medical direct costs related to psoriasis were $€ 2,166.2$ on an annual basis: $38.8 \%$ for hospitalisation, $18.0 \%$ for day hospital services, $7.4 \%$ for specialist visits, $23.6 \%$ for laboratory tests, $4.5 \%$ for diagnostic procedures and $7.8 \%$ for psoriasis drugs.

Following the switch to biologic therapy, mean costs rose, due to the higher cost of the drugs $(+8,003.5 \%)$, whereas other costs dropped ( $-33.0 \%)$, particularly, as expected, the cost of hospitalisation. The new cost breakdown at the end of the follow-up period is therefore $3.7 \%$ for hospitalisation, $1.9 \%$ for day hospital services, $0.8 \%$ for specialist visits, $2.4 \%$ for laboratory tests, $0.1 \%$ for diagnostic procedures and $91.1 \%$ for drugs. The mean total cost increase was $€ 12,907.60$ on an annual basis (Tables 4 and 5).

\subsubsection{Incremental Cost-Effectiveness Ratio}

The ICER of the switch to biologic therapies, from the perspective of the Italian health service, of patients with plaque psoriasis in real practice settings in the centres participating in the project is $€ 28,656.3$ per QALY gained, a value that would appear to be socially acceptable according to the most authoritative HTA agencies [16]. Although it refers to a very short observation period, this 


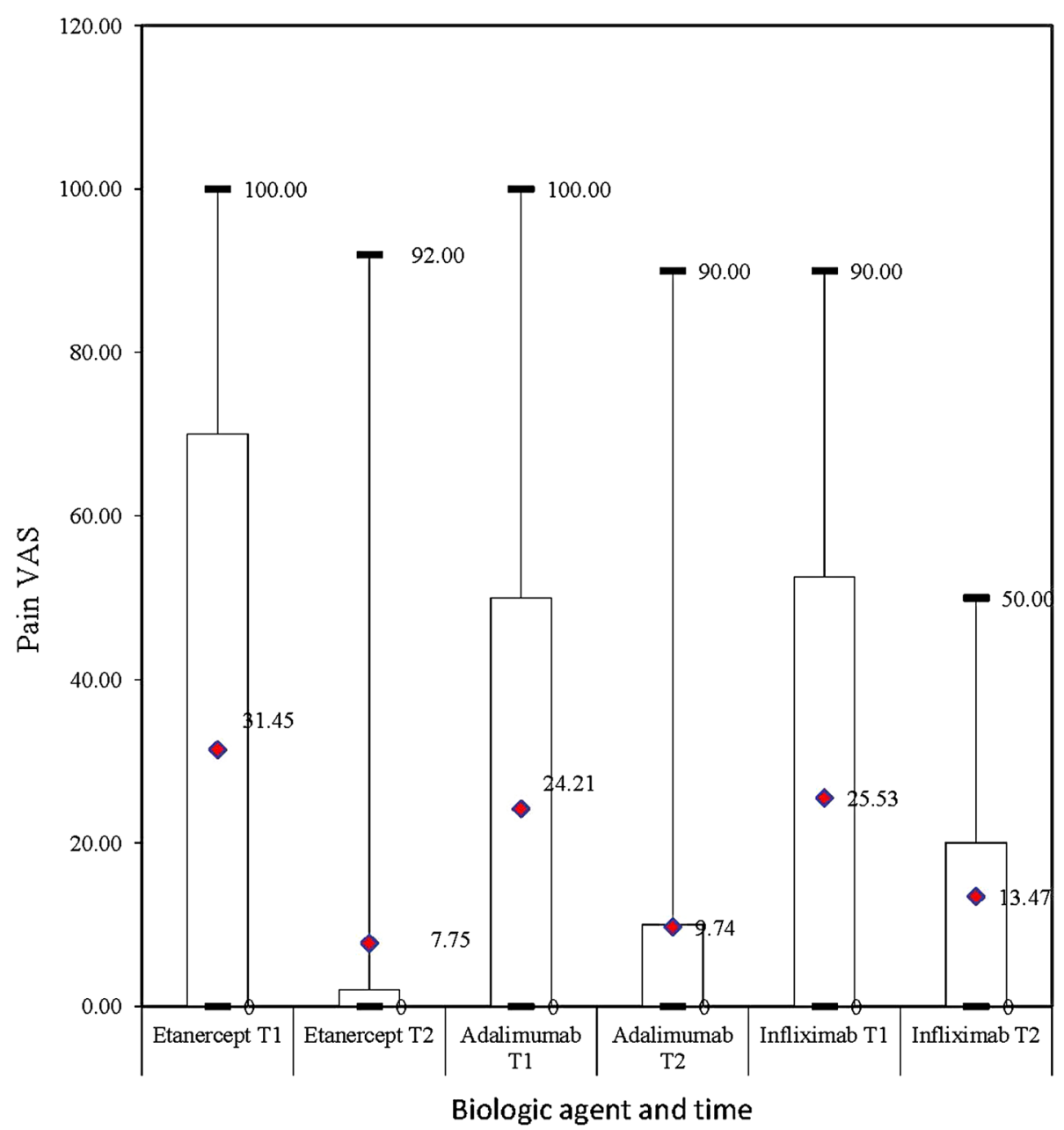

Fig. 2 Pain visual analogue scale (VAS) level

value is lower than that stated in the international literature [8, 17-19] for the single agents, as well as in the studies performed for their authorisation.

Although the differences in terms of benefit between the single compounds are not statistically significant, ${ }^{4}$ for patients treated with etanercept ${ }^{4}$ the incremental cost per QALY gained is €25,839.8, compared with $€ 29,285.3$ for adalimumab and $€ 53,525.4$ for infliximab (Table 6).

The incremental cost was $€ 513.0$ per PASI point, $€ 328.8$ per pain VAS point and $€ 268.2$ per itching VAS point. The incremental cost per PASI point gained was $€ 504.3$ with etanercept, €493.8 with adalimumab and $€ 706.7$ with infliximab. The cost per pain and itching VAS point gained was $€ 270.8$ and $€ 250.1$ with etanercept, $€ 370.7$ and $€ 252.4$

\footnotetext{
${ }^{4}$ It should be noted that in real practice we observe switches between drugs, and that patients have been assigned to the drug group at enrolment (first biologic agent prescribed).
}

with adalimumab, and $€ 983.2$ and $€ 523.9$ with infliximab (Table 6).

\subsection{Sensitivity Analyses}

Univariate and probabilistic sensitivity analyses were performed. The results of the univariate sensitivity analysis are shown in the Tornado diagram (Fig. 4). Analysis focused, more specifically, on the change in HR-QOL benefits (for the whole sample) obtained by the limits of the confidence levels (95\% CI 0.21-0.23) and the $10 \%$ change in the individual cost items (hospitalisation, specialist appointments, laboratory tests and diagnostic procedures). The results of the deterministic sensitivity analysis show that the ICER always remains below the $€ 32,000$ per QALY threshold, which suggests that the results are quite robust (Fig. 4).

Probabilistic sensitivity analysis has been performed, assuming gamma distributions for the cost, and beta for 
Fig. 3 Itching visual analogue scale (VAS) level

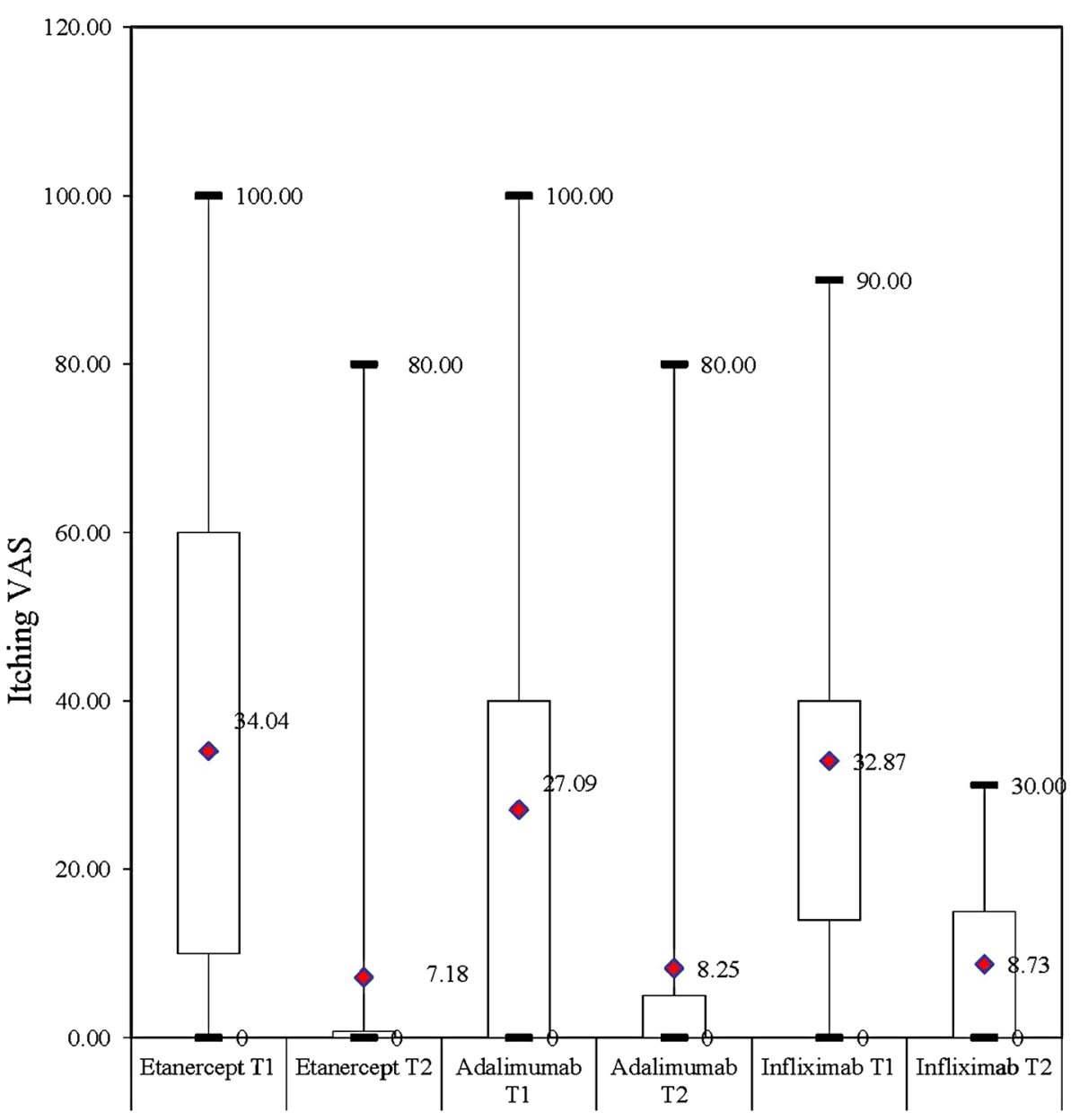

Biologic agent and time
QALYs. The probabilistic sensitivity analysis indicates that biologic therapies for psoriasis are cost effective, with a $€ 30,000$ threshold $^{5}$ in $64.1 \%$ of cases and a $€ 40,000$ threshold in $96.2 \%$ of cases (Fig. 5).

\section{Discussion}

The cost of psoriasis patients in Italy is very high. As reported by Finzi et al. [20], hospitalisation constituted the largest component cost for the treatment of psoriasis in the past; but now, thanks to systemic and biologic agents, this cost is much lower [21].

The costs of treatment with biologics are significantly higher than those of conventional systemic therapy and vary from US\$13,000 to US\$30,000 [22]. Despite this, the cost effectiveness of biologic therapy has been extensively proven.

\footnotetext{
5 Consider that the average cost-effectiveness analysis in Italy amounted to $€ 28,000$. In the literature this is reported as $£ 30,000$ (approximately €36,000) [26].
}

The UK National Institute for Health and Clinical Excellence (NICE) has published a number of technology appraisals on biologics using the evidence obtained in preapproval studies [17, 19, 23, 24].

In the first report [17], NICE analysed the cost effectiveness of etanercept and efalizumab according to the authorised indications for the treatment of psoriasis, and concluded that efalizumab was more expensive and less efficacious than etanercept $25 \mathrm{mg} \times 2$ per week as intermittent therapy: the ICER was found to be $£ 24,346$ and $£ 15,297$ per QALY gained, respectively. The ICERs for etanercept $25 \mathrm{mg} \times 2$ as continuous therapy and etanercept $50 \mathrm{mg} \times 2$ as intermittent therapy, on the other hand, were $£ 23,905$ and $£ 43,395$, respectively [17]. Consequently, on the basis of the clinical evidence available, etanercept was recommended by NICE for the treatment of adults with psoriasis with a PASI score of PASI $\geq 10$ and Dermatology Life Quality Index (DLQI) score $>10$, and who are non-responders to, intolerant to, or have contraindications for systemic treatment with cyclosporin, methotrexate or psoralen and UVA phototherapy (PUVA) [17]. 
Table 2 Clinical benefits and quality of life

\begin{tabular}{cllll}
\hline & \multicolumn{3}{l}{ Group (number of patients) } & \\
\cline { 2 - 5 } & $\begin{array}{l}\text { All } \\
(178)\end{array}$ & $\begin{array}{l}\text { Etanercept } \\
(106)\end{array}$ & $\begin{array}{l}\text { Adalimumab } \\
(57)\end{array}$ & $\begin{array}{l}\text { Infliximab } \\
(15)\end{array}$ \\
\hline HR-QOL & & & & \\
Enrolment & 0.58 & 0.62 & 0.52 & 0.60 \\
$\Delta$ & 0.23 & 0.23 & 0.21 & 0.21 \\
$p$ value* & 0.000 & 0.000 & 0.000 & 0.001 \\
VAS & & & & \\
Enrolment & 57.06 & 60.29 & 49.96 & 61.20 \\
$\Delta$ & 19.89 & 19.03 & 23.51 & 12.20 \\
$p$ value* & 0.000 & 0.000 & 0.000 & 0.009 \\
PASI & & & & \\
Enrolment & 21.57 & 23.58 & 17.98 & 21.01 \\
$\Delta$ & 12.58 & 14.35 & 9.77 & 10.76 \\
$p$ value* & 0.000 & 0.000 & 0.000 & 0.006 \\
Pain VAS & & & & \\
Enrolment & 28.43 & 31.45 & 24.21 & 25.53 \\
$\Delta$ & 19.63 & 23.70 & 14.47 & 12.07 \\
$p$ value* & 0.000 & 0.000 & 0.000 & 0.142 \\
Itching VAS & & & & 32.87 \\
Enrolment & 31.71 & 34.04 & 27.09 & 0.009 \\
$\Delta$ & 24.06 & 26.86 & 18.84 & 0.000 \\
$p$ value* & 0.000 & 0.000 & & \\
\hline
\end{tabular}

$H R-Q O L$ health-related quality of life, PASI Psoriasis Area and Severity Index, $V A S$ visual analogue scale

* Paired $T$ test

In 2008, NICE extended its evaluation to infliximab, which is recommended for the treatment of adults with severe psoriasis (PASI $>20$ and DLQI $>18$ ) who are nonresponders to, intolerant to, or present with contraindications for systemic treatment [23]. Again in 2008, NICE also evaluated adalimumab, concluding that the ICER per QALY gained with adalimumab compared to supportive care is $£ 30,500$ and that adalimumab is superior to etanercept when administered as continuous treatment [19]. The same report states that the ICER for etanercept versus supportive care rises from $£ 37,300$ for continuous therapy to $£ 27,600$ for intermittent therapy [19]. In 2009, NICE also evaluated ustekinumab, comparing it to etanercept, adalimumab and infliximab [24].

Many subsequent studies have re-confirmed the costeffectiveness of biologics for the treatment of psoriasis. Heinen-Kammerer et al. [18] conducted an analysis of the cost effectiveness of etanercept compared to systemic treatment, concluding that in patients with a baseline PASI and DLQI of $>10$, the ICER compared with systemic treatment is $€ 45,491$. Considering patients with a PASI $>15$ and DLQI $>20$, the ICER drops to $€ 32,058$ and $€ 18,154$, respectively [18].
Table 3 Differences in clinical and quality of life benefits between drugs

\begin{tabular}{cccc}
\hline & $\begin{array}{l}\text { Etanercept vs. } \\
\text { infliximab }\end{array}$ & $\begin{array}{l}\text { Etanercept vs. } \\
\text { adalimumab }\end{array}$ & $\begin{array}{l}\text { Infliximab vs. } \\
\text { adalimumab }\end{array}$ \\
\hline HR-QOL & 0.03 & 0.02 & 0.00 \\
$p$ value & $0.608^{\mathrm{a}}$ & $0.657^{\mathrm{b}}$ & $0.913^{\mathrm{a}}$ \\
VAS & 6.83 & -4.48 & -11.31 \\
$p$ value & $0.302^{\mathrm{b}}$ & $0.280^{\mathrm{b}}$ & $0.039^{\mathrm{a}}$ \\
PASI & 1.82 & 2.81 & 0.99 \\
$p$ value & $0.494^{\mathrm{c}}$ & $0.121^{\mathrm{c}}$ & $0.805^{\mathrm{b}}$ \\
Pain VAS & 11.63 & 9.22 & -2.41 \\
$p$ value & $0.075^{\mathrm{c}}$ & $0.187^{\mathrm{c}}$ & $0.774^{\mathrm{b}}$ \\
Itching VAS & 2.73 & 8.02 & 5.29 \\
$p$ value & $0.751^{\mathrm{b}}$ & $0.125^{\mathrm{c}}$ & $0.405^{\mathrm{c}}$ \\
\hline
\end{tabular}

HR-QOL health-related quality of life, PASI Psoriasis Area and Severity Index, $V A S$ visual analogue scale

a One simple $T$ test, equal variances not assumed

b One simple $T$ test, equal variances assumed

c Wilcoxon test

In one American study conducted using a simulation model [25], the cost per patient was US $\$ 28,767$ for etanercept $25 \mathrm{mg} \times 2$, US $\$ 29,129$ for etanercept with stepdown treatment and US\$37,959 for etanercept $50 \mathrm{mg} \times 2$. Alefacept and efalizumab were found to be superior to etanercept $25 \mathrm{mg} \times 2$.

Sizto et al. [8] performed a comparative cost-effectiveness analysis for biologics that concluded that adalimumab is the most cost-effective agent, with an ICER of $£ 30,538$ per QALY, followed by etanercept 25 and $50 \mathrm{mg}$ ( $£ 37,284$ and $£ 37,676$ per QALY, respectively), efalizumab ( $£ 40,000$ per QALY) and infliximab ( $£ 42,492$ per QALY).

The purpose of our analysis was to verify if values predicted with RCT evidence and economic modelling could be confirmed in real practice settings in Italy. The analysis not only applies to a real Italian population, but also aimed to confirm the HR-QOL benefit predicted by recording data directly for Italian patients.

Significant improvements were confirmed for all the objective and subjective clinical parameters considered. During the, albeit limited, duration of the follow-up period, the results appeared to be on average even better than those indicated in literature. The benefit in terms of HR-QOL were also significant.

The results obtained, although with some significant limitations (as previously mentioned and discussed below), seems to confirm the findings of social acceptability (in terms of cost per QALY) of biologic therapy predicted in the literature with models and the basis of trial evidence, hence on controlled populations, in the real practice of leading specialist centres in Italy also. 
Table 4 Medical direct costs ( $€$; year 2009), on an annual basis, borne by the Italian health service per patient

\begin{tabular}{|c|c|c|c|c|c|c|c|}
\hline & Hospitalisation & $\begin{array}{l}\text { Day } \\
\text { hospital }\end{array}$ & $\begin{array}{l}\text { Specialist } \\
\text { appointments }\end{array}$ & $\begin{array}{l}\text { Laboratory } \\
\text { tests }\end{array}$ & $\begin{array}{l}\text { Diagnostic } \\
\text { procedures }\end{array}$ & Drugs & Total \\
\hline Prior to enrolment & 840.74 & 389.18 & 159.70 & 510.50 & 96.54 & 169.50 & $2,166.16$ \\
\hline $\begin{array}{l}\text { Observation } \\
\text { period }\end{array}$ & 560.50 & 279.20 & 126.74 & 363.56 & 8.34 & $13,735.40$ & $15,073.74$ \\
\hline$\Delta$ Costs & -280.24 & -109.98 & -32.96 & -146.94 & -88.20 & $13,565.90$ & $12,907.58$ \\
\hline
\end{tabular}

The costs for patients who switched from one agent to another were calculated using the agent prescribed at enrolment if the patient switched treatment after 3 months and using the agent the patient switched to if the switch took place after less than 3 months from initial prescription

Table 5 Increase in the medical direct costs borne by the Italian health service (on an annual basis)

\begin{tabular}{ll}
\hline Group & $\Delta$ Costs $(€)$ \\
\hline All & $12,907.58$ \\
Etanercept & $12,129.10$ \\
Adalimumab & $12,425.20$ \\
Infliximab & $22,252.28$ \\
\hline
\end{tabular}

Table 6 Incremental cost-effectiveness ratio

\begin{tabular}{llllll}
\hline Group & QALY & VAS & PASI & $\begin{array}{l}\text { Pain } \\
\text { VAS }\end{array}$ & $\begin{array}{l}\text { Itching } \\
\text { VAS }\end{array}$ \\
\hline All & $28,656.31$ & 324.47 & 513.01 & 328.78 & 268.22 \\
Etanercept & $25,839.79$ & 318.68 & 504.30 & 270.81 & 250.20 \\
Adalimumab & $29,285.34$ & 264.25 & 493.77 & 370.68 & 252.39 \\
Infliximab & $53,525.38$ & 911.98 & 706.07 & 983.24 & 523.95
\end{tabular}

PASI Psoriasis Area and Severity Index, $Q A L Y$ quality-adjusted lifeyear, VAS visual analogue scale

\subsection{Limitations of this Study}

The main limit of our analysis was the short observation period which, for example, did not allow us to assess fully the impact of biologic treatment interruptions and use of intermittent therapies, as well as persistency of the treatment effect (and, consequently, constancy of costs). This would be of interest both in terms of clinician's behaviour and patient adherence and compliance, but would be appreciable only in the long term.

In addition, it is important to bear in mind that this is an observational study, with no control group: consequently, ICER calculation is not perfectly comparable with that of previous analyses based on RCT evidence: our calculation could be considered a conservative hypothesis, assuming that, without switching to biologic treatment, the patients' state of health and costs incurred would remain constant.

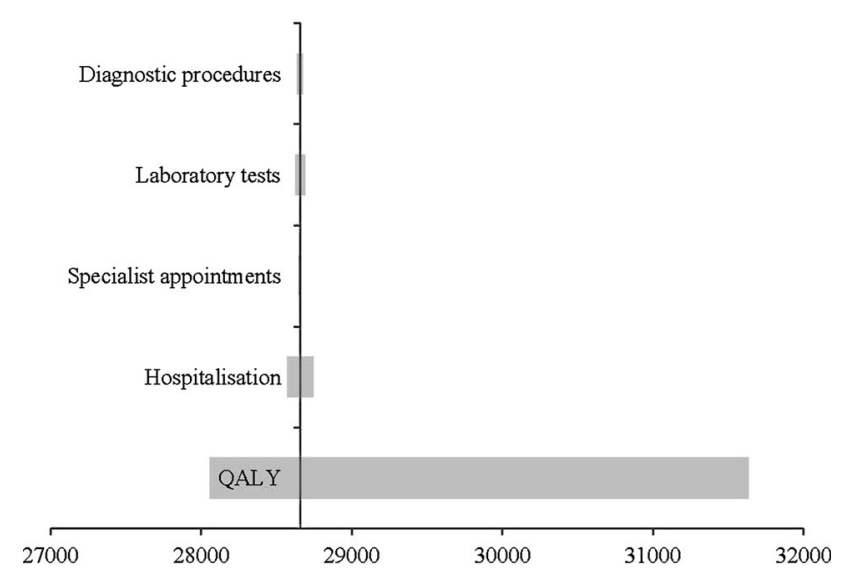

Fig. 4 Tornado diagram. $Q A L Y$ quality-adjusted life-year

Also, despite certain differences between the agents used, the substantial cost effectiveness of all the agents prescribed by physicians was confirmed, but the size of the cohort enrolled did not make it possible to detect any statistically significant differences between the various drugs used.

\section{Conclusions}

Findings from our analysis, conducted by recording Italian data directly in real clinical practice settings, are in line with the predictions from models based on RCT and economic modelling, in terms of both efficacy and cost effectiveness.

The benefits of biologic therapy were found to be statistically significant according to a number of clinical (PASI, pain VAS and itching VAS) and HR-QOL-related parameters. More specifically, the study allowed for the validation, for the Italian population in particular, of the benefits in terms of quality of life, since the gain in QALYs was elicited directly from the patients enrolled.

The study also confirms that in the clinical practice of the participating Italian centres, the cost per QALY achieved, although from a short observation period, is 
Fig. 5 Acceptability curve. $Q A L Y$ quality-adjusted life-year

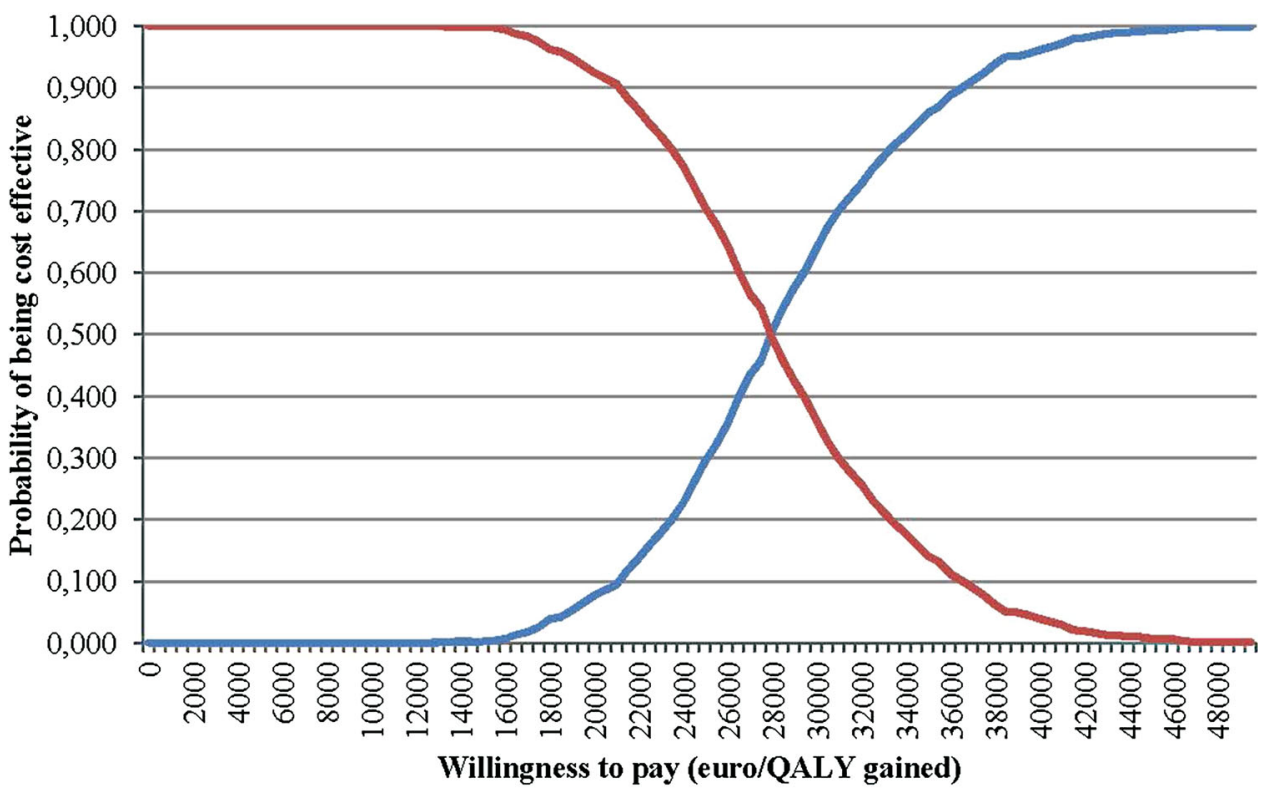

$\longrightarrow$ Biologic therapies $\longrightarrow$ Conventional systemic therapies comparable with results published in the most authoritative international HTA reports.

This analysis confirmed the substantial 'cost-utility' of the biologic therapies, as well as of all the compounds prescribed; although a number of differences were observed among the products used, the sample size made it impossible for any calculation of statistical significance.

The main limit of our analysis was the short observation period, which did not allow us to assess fully the impact of biologic treatment interruptions or intermittent etanercept therapy, as well as persistency of the treatment effect.

A certain degree of caution is required concerning the transferability of the results, since the participating centres are specialised facilities that are monitored as part of the Psocare project and are therefore presumably more attentive to the appropriateness of treatment choices: the study does, however, show that correct use of biologic therapy is also cost effective in clinical practice and therefore in 'real' patient populations.

Acknowledgments Editorial assistance was provided by HPSHealth Publishing \& Services Srl, Italy—and funded by Pfizer, Italy.

Statement of funding sources The study was funded by Pfizer, Italy.

Conflict of interest disclosures SF has received research and educational grants from BMS, MSD Italia, Celgene, Medtronic, Abbott, Bayer and Daiichi Sankyo. AF has been consultant for Abbott, Janssen-Cilag, MSD, Novartis, Pfizer and has received support for travel to meeting from the above mentioned companies. CS has been consultant and/or speaker for Merck, Pfizer, Abbvie, Novartis, Janssen-Cilag and Leo Pharma. GG has received lecture and/or consultation fees from Pfizer, Novartis, Abbvie, Janssen, Eli-Lilly,
MSD, Almirall and Celgene. PA has received fees as speaker or consultant or has received research or educational support for the Dermatology Unit of the Department of Medicine of the University of Padua from: Abbott, Almirall, MSD, Janssen-Cilag, Pfizer, GSK and Leo Pharma. VGA has been a speaker, consultant and/or a member of Advisory Board for Abbvie, MSD, Novartis, Pfizer, Janssen-Cilag and Leo Pharma.

Open Access This article is distributed under the terms of the Creative Commons Attribution Noncommercial License which permits any noncommercial use, distribution, and reproduction in any medium, provided the original author(s) and the source are credited.

\section{References}

1. Epidemiology GD. In: Gordon KB, Ruderman EM, editors. Psoriasis and psoriatic arthritis: an integral approach. Heidelberg: Springer; 2005. p. 57-65.

2. Griffiths CE, Barker JN. Pathogenesis and clinical features of psoriasis. Lancet. 2007;370(9583):263-71.

3. Saraceno R, Griffiths CE. A European perspective on the challenges of managing psoriasis. J Am Acad Dermatol. 2006;54(3 Suppl 2):S81-4.

4. Gisondi P, Girolomoni G. Psoriasis and atherothrombotic diseases: disease-specific and non-disease-specific risk factors. Semin Thromb Hemost. 2009;35(3):313-24.

5. Esposito M, Saraceno R, Giunta A, et al. An Italian study on psoriasis and depression. Dermatology. 2006;212(2):123-7.

6. Lebwohl M. Psoriasis. Lancet. 2003;361(9364):1197-204.

7. Wong JW, Nguyen TV, et al. Quality-of-life instruments: evaluation of the impact of psoriasis on patients. Dermatol Clin. 2012;30(2):281-91.

8. Sizto S, Bansback N, Feldman SR, et al. Economic evaluation of systemic therapies for moderate to severe psoriasis. Br J Dermatol. 2009;160(6):1264-72. 
9. Finzi AF, Lloyd A, Scott DA, et al. Psoriasi: costo del trattamento della psoriasi grave in 7 paesi europei.ASNPV. 2004;16, Anno nono, Maggio 2004;4-6.

10. Colombo G, Altomare G, Peris K, et al. Moderate and severe plaque psoriasis: cost-of-illness study in Italy. Ther Clin Risk Manag. 2008;4(2):559-68.

11. De Compadri P, Koleva D. I costi della psoriasis vulgaris nei pazienti sottoposti a terapia sistemica: una rassegna della letteratura e una stima preliminare di costo in Italia. Quaderni di farmaco economia. 2008;6:7-15.

12. EQ-5D 3L User Guide. Prepared by Mandy Oemar/Mark Oppe, last version October 2013. http://www.euroqol.org/fileadmin/user_ upload/Documenten/PDF/Folders_Flyers/EQ-5D-3L_UserGuide_ 2013_v5.0_October_2013.pdf. Accessed 28 Jan 2014.

13. Griffiths CE, Clark CM, Chalmers RJ, et al. A systematic review of treatments for severe psoriasis. Health Technol Assess. 2000;4(40):1-125.

14. Gordon KB, Gottlieb AB, Leonardi CL, et al. Clinical response in psoriasis patients discontinued from and then reinitiated on etanercept therapy. J Dermatolog Treat. 2006;17(1):9-17.

15. Carey W, Glazer S, Gottlieb AB, et al. Relapse, rebound, and psoriasis adverse events: an advisory group report. J Am Acad Dermatol. 2006;54(4 Suppl 1):S171-81.

16. National Institute for Health and Clinical Excellence (NICE). Guide to the methods of technology appraisal. 2013. http://www.nice.org. uk/media/D45/1E/GuideToMethodsTechnologyAppraisal2013.pdf. Accessed Dec 2013.

17. National Institute for Health and Clinical Excellence (NICE). Etanercept and efalizumab for the treatment of adults with psoriasis. 2006. http://publications.nice.org.uk/etanercept-and-efalizumab-forthe-treatment-ofadults-with-psoriasis-ta103. Accessed Dec 2013.

18. Heinen-Kammerer T, Daniel D, Stratmann L, et al. Cost-effectiveness of psoriasis therapy with etanercept in Germany. J Dtsch Dermatol Ges. 2007;5(9):762-8.
19. National Institute for Health and Clinical Excellence (NICE). Adalimumab for the treatment of adults with psoriasis. 2008. http://www.nice.org.uk/nicemedia/live/12007/41002/41002.pdf. Accessed Dec 2013.

20. Finzi AF, Mantovani LG, Belisari A. The cost of hospital-related care of patients with psoriasis in Italy based on the AISP study. Associazione Italiana Studi Psoriasi. J Eur Acad Dermatol Venereol. 2001;15(4):320-4.

21. Calzavara-Pinton PG, Rossi MT, Piovanelli P, et al. The main organizational changes in dermatological practice in the Lombardy Region, Italy, from 2001 to 2009. J Eur Acad Dermatol Venereol. 2013;27(2):206-13.

22. Miller DW, Feldman SR. Cost-effectiveness of moderate-tosevere psoriasis treatment. Expert Opin Pharmacother. 2006;7(2): 157-67.

23. National Institute for Health and Clinical Excellence (NICE). Infliximab for the treatment of adults with psoriasis. 2006. http://www. nice.org.uk/nicemedia/live/11910/38954/38954.pdf. Accessed Dec 2013.

24. National Institute for Health and Clinical Excellence (NICE). Final appraisal determination ustekinumab for the treatment of moderate to severe psoriasis. 2009. http://www.nice.org.uk/ nicemedia/pdf/TA180Guidance.pdf. Accessed Dec 2013.

25. Wanke LA, Malone D, Chiou CF, Wolley M. Cost efficacy comparison of biologics in the treatment of psoriasis. J Am Acad Dermatol. 2004;50(3 Suppl):179.

26. Russo P. La valutazione farmacoeconomica nel contesto regolatorio italiano, analisi quali-quantitativa dei dossier di richiesta del prezzo e della rimborsabilità. Pharmacoecon Ital Res Artic. 2008;10(2):59-75. 